Opinion

\title{
Moving beyond seed storage in tackling plant loss: linking seed collection and re-introduction
}

\author{
Ganesh K. Jaganathan and Bao-lin Liu \\ Department of Biothermal Engineering, University of Shanghai for Science and Technology, Shanghai 20009, China
}

Article history

Received: 5 March 2016

Accepted: 18 March 2016

Published online: 1 April 2016

(C) Jaganathan \& Liu 2016

Publisher

Horizon e-Publishing Group

Corresponding Author

Ganesh K. Jaganathan

区iganeshcbe@gmail.com

\begin{abstract}
Globally, plants are becoming extinct at an unprecedented rate. Seed banking is considered as the most cost-effective technique to preserve many conservation concern species. From a practical standpoint, however, banking seeds is essentially just the first step in tackling plant loss, as the real-life challenge lies in how well these seeds when re-introduced become whole plants and maintain species count. In the current model, merely very few seed banks extend their efforts in re-introduction problems. Compelling evidence suggests that many re-introduction efforts are less than successful. Such axiom convicts seed banks must also participate in the 'post-storage' process and engage working with other ecologists, physiologists and re-introduction practitioners to devise a robust re-introduction practice and exchange information about the seed lot including collection site, maternal environment etc. Bridging these gaps would facilitate enhanced restoration practice and pave way for efficient reconstruction of the ecosystem.
\end{abstract}

Keywords

climate change; conservation; seed banks; re-introduction; ecosystem

Jaganathan, G. K. and Liu, B. 2016. Moving beyond seed storage in tackling plant loss: linking seed collection and re-introduction. Plant Science Today 3(2): 68-71. http://dx.doi.org/10.14719/pst.2016.3.1.202

\section{Introduction}

Globally, plants are becoming extinct at an unprecedented rate. Despite the growing awareness on conserving threatened flora, the pace at which plant loss occurs has intensified 10-to 100 fold in the recent years leading to vibrant challenges for conserving at least the remnant species (Corvalan et al., 2005). To preserve plant diversity, several conservation measures are being planned often one approach complementing other- amongst which banking seeds is possibly the most cost-effective, yet promising technique to preserve many species (Hay and Probert, 2013). Seeds collected from wild and dried to lower moisture contents (3-10\% moisture on fresh weight basis) can be held at low temperatures (e.g. $-196^{\circ} \mathrm{C}$ ) for centuries without any alterations to genetic makeup or viability, thus offering great advantage both in space and time (Walters et al., 2013). The fact that changing climate may impose serious threats to any species has underpinned the need for banking seeds of possibly all species. In order to meet this elaborate goal, seed banks around the world are ambitiously attempting to collect large quantities of seeds and a great deal of money exceeding several million dollars is spent to ensure the global flora is preserved (Walck and Dixon, 2009; Hay and Probert, 2013).

A timely question tied to the seed storage practice is does successful banking of seeds imply the species are effectively conserved? Current state-ofart promises that the stored seeds containing future 
plants, once stored at low temperatures do not undergo any metabolic activity, thereby providing genetic materials for species even if the species had gone extinct in wild (Hay and Probert, 2013). However, the crux of this problem goes beyond this simplified acceptance. Seed storage is essentially just the first step in embarking the unabridged problem. Although gene banks aim to store seeds for longer time as an insurance policy, these seeds are not meant to be stored interminably (Hamilton, 1994). Further, there are many seeds which are stored for short-time and supplied when required for sowing in wild. In real world scenario, the tangible challenge lies in successfully re-introducing the stored seeds in suitable habitats, in a way that those seeds grow to full plants, reproduce and produce next generation seeds without any assistance to maintain species count (Hamilton, 1994; Guerrant Jr and Pavlik, 1998).

When viewed from this perspective, the extent to which seed banks fulfil the intended tasks of conservation per se depends on how well the reintroductions are planned (Husband and Campbell, 2004). Most seed banks consider collection, cleaning, processing and storage of seeds as their pivotal roles, with viability assessments during storage also form an integral part. Thus, seed banks take less participation in the 'tail-ended' events of converting stored seeds in to whole plants in the wild (Maunder et al., 2004). However, seed banks have distinctive roles in ensuring the stored seeds are utilized in a more valuable way to restore the species that had been or becoming lost, otherwise the efforts are futile. Thus, one of the tenacious issues for seed banks is to efficiently formulate highly resourceful reintroduction protocols in conjugation with other re-introduction practitioners. This is a daunting task especially when re-introductions are planned at community level because every species require certain amount of space and specific demand to complete life-cycles (Margules and Pressey, 2000). Nevertheless, to achieve such as irksome goal, seed banks must tackle various constrains and approach the problem from systematic multidimensional standpoints, if not extinction of reintroduced species will be the consequence.

Some hundreds of hectares are cleared every year for creating living space and agricultural purposes for the ever increasing population (Achard et al., 2002). Due to the effects of global warming, more vegetation are becoming patchy and numerous species are susceptible to substantial biotic and abiotic pressure (Achard et al., 2002; Malhi et al., 2008). It has become a common practice to prioritize endangered species collection in many countries, where funding for plant conservation particularly to seed storage is extremely limited (Farnsworth et al., 2006). However, practicing these approaches requires reassessment, because the area of deforestation is extremely high and many species having extremely specific growing conditions, present only in a smaller region will be lost (Pressey and Taffs, 2001; Husband and Campbell, 2004; Bachmann et al., 2013). Most of the accessions held in seed banks are skewed towards horticultural crops, leaving rare or endangered species more vulnerable (Godefroid et al., 2011). This means seed banks must systematically devise when, where and how to collect the seeds of multiple species. Since the seed maturation time varies with species and habitats, it is important that more than one collection time per year is planned based on the location and seeds must be immediately transformed to storage conditions. More importantly, care must be taken not to disturb the natural re-establishment process, especially if the collected species is endangered or threatened, which has lesser number of plants and limited turn-over of seed counts (Menges, 1998).

Knowledge on re-introductions are lagging behind the seed storage practice (Guerrant Jr and Kaye, 2007). One of the important bottleneck is to envisage when and where the species stored in the form of seeds will be re-introduced (Fiedler and Laven, 1996; Guerrant Jr and Kaye, 2007). To this end, economic and political motives often influence site selection for re-introduction. Notably more re-introduction sites are often established in remote or landscapes not suitable for agriculture (Osborne and Seddon, 2012). However, re-introduction site must have the identical or at least similar conditions on which the collected seeds could have otherwise germinated (Maunder, 1992). In addition, reintroduction site needs to be undisturbed by direct or indirect human activities for long-time. One way to do this is by expanding the 'in-situ reserves' already established. This approach would minimize the risk of species threatened by patchy vegetation. Nevertheless, the underlying problem with this practice is the introduction of species to new habitat, presumably as invasive species, which might affect the endemic species of introduced ecosystem. Thus, not all species are suited for growing in or around reserves, as some $70-85 \%$ of the reserves are established near the mountains or other drier landscapes (Achard et al., 2002). This raises an important challenge, if a particular forest space is converted for other purpose, whether the seeds collected from that region bears any significance in restoring the vegetation.

These facts underpin seed banks to take more responsibilities by engaging with policy-makers and government authorities to optimize the site selection and re-introduction methodology. First, it may seem tedious, seed banks must start working with ecologists, physiologists and conservationists to explore why a particular species that merits storage actions is becoming conservation concern. This involves complex understanding of species interactions at ecosystem level, reproduction biology, germination ecology, environmental stress 
etc. Second, seed banks must team up with academic researchers and other practitioners who are enthralled with re-introduction to conduct a 'miniature experiment' in the field, possibly involving complex-network of species, using stored seeds to understand the problems of the reintroduced species might face in wild during establishment before large-scale re-introductions are planned. When planning re-introductions based on the study results, necessary steps should be taken to minimise the risks, failure to do this will inevitably push the re-introduced species becoming extinct again in the near future. One case study offered by Johnson et al. (2004) is that in a Douglas-fir provenance plantation, plants grown from re-introduced seed sources from different sites suffered more damage during an unusual cold spell compared with local populations. Our ongoing studies on tropics also reveal similar conclusion. Briefly, our results demonstrate that plants growing from seeds from local vegetation survive severe drought than seeds from slightly moderate conditions. These pattern invokes a special attention when planning reintroduction of stored seeds.

Examples pertaining to whether or not seeds of conservation concern species effectively reintroduced in wild are scarce. Most of the seed banks aim to store seeds for longer time. According to Walck and Dixon (2009) when the seeds collected in the present environmental conditions are banked for longer time and reintroduced in the wild after several decades or centuries the environment at which these seeds have to germinate and establish would be very different than these seeds were adapted to. Hence, they recommended collecting seeds of each species at regular intervals to ensure more seeds are establishing to full plants in future climatic conditions. As such, this notion questions the storage of seeds for centuries as an insurance policy against plant loss, because these seeds having lesser ability to grow in future climate. The destruction of forest results in forced reintroduction of seeds in to other sites. Theilade and Petri (2003) noted that the seeds of Sophora toromiro, an extinct tree of Easter Island, has been successfully collected and stored from the last tree in 1960. These seeds were stored initially in Naturhistoriska Riksmuseet in Stockholm and later transferred to Gothenburg Botanical Gardens. The success of re-introduction of this tree will largely depend on many factors such as the present environmental conditions, the co-existing species etc. The change in vegetation from the seed maturation time and the time of re-introduction would have serious impact on the re-introduced seeds (Cogoni et al., 2013). Therefore, information on the seed maturation site must be taken in to account when planning the re-introduction protocols. Seed banks must engage in transforming the information of seed origin and play a role in site selection for re-introduction. In case the stored seeds are used for re-introduction, the lesser involvement of seed bank in these process could often lead to less successful results.

While it may seem that the issue of reintroduction is less inclined to the overarching aim of 'seed storage' by seed banks, the steady increase in plant loss due to the climate change calls for an extensive participation of seed bank in converting the stored seeds in to whole plants and further collect seeds from the re-introduced species. Seeds collected from one country and stored in a different country can be re-introduced in a very different place. Demand for the species often results in using stored seeds of any origin when reintroduction projects are initiated. As the present model for re-introduction does not require the direct participation of seed banks in reintroduction, as the 'post-bank' period is handled by different expertise, results of many reintroduction projects are often less successful (Maunder, 1992; Faulk et al., 1996). With lesser information available to the re-introduction practitioners about the seed maturation site, climate etc., there is an increased chance seeds collected from a particular site end up germinating and growing in a less hostile site, presumably posing serious risk for successful plant growth. This situation convinces the joint action of seed banks in re-introduction projects. Needless to mention, coping up with all these goals will be lamentably arduous in the present situation, but if the precious money and effort being spent on banking seeds for decades are to be exploited in reconstructing our ecosystem, seed banks must inevitably take steps to meet these challenges.

\section{Competing interests}

The authors declare that they have no competing interests.

\section{References}

Achard, F., H. D. Eva, H.-J. Stibig, P. Mayaux, J. Gallego, T. Richards, and J.-P. Malingreau. 2002. Determination of deforestation rates of the world's humid tropical forests. Science 297: 9991002. doi: 10.1126/science.1070656

Bachmann, P., M. Köhl, and R. Päivinen. 2013. Assessment of biodiversity for improved forest planning. Springer Science \& Business Media Vol 51.

Cogoni, D., G. Fenu, E. Concas, and G. Bacchetta. 2013. The effectiveness of plant conservation measures: the Dianthus morisianus reintroduction. Oryx 47: 203-206. doi: 10.1017/S003060531200169X

Corvalan, C., S. Hales, and A. McMichael. 2005. Assessment, Millennium Ecosystem (2005). Ecosystems and human well-being: Biodiversity Synthesis. World Resources Institute, Washington, DC. USA Vol 5.

Farnsworth, E., S. Klionsky, W. Brumback, and K. Havens. 2006. A set of simple decision matrices for prioritizing collection of rare plant species for 
ex situ conservation. Biol Conserv 128: 1-12. doi: 10.1016/j.biocon.2005.09.010

Faulk, D., C. Miller, and M. Olwell. 1996. Restoring diversity: strategies for reintroduction of endangered plants. Island Press.

Fiedler, P. L., and R. D. Laven. 1996. Selecting reintroduction sites. Restoring diversity Island Press, Washington, DC: 157-169

Godefroid, S., S. Rivière, S. Waldren, N. Boretos, R. Eastwood, and T. Vanderborght. 2011. To what extent are threatened European plant species conserved in seed banks? Biol Conserv 144: 14941498. doi: 10.1016/j.biocon.2011.01.018

Guerrant Jr, E. O., and T. N. Kaye. 2007. Reintroduction of rare and endangered plants: common factors, questions and approaches. Aust J Bot 55: 362-370. doi: 10.1071/BT06033

Guerrant Jr, E. O., and B. M. Pavlik. 1998. Reintroduction of rare plants: genetics, demography, and the role of ex situ conservation methods. In: Conservation biology for the coming Decade. P. L. Fiedler and P. M. Kareiva, Eds. Springer, London. p. 80-108.

Hamilton, M. B. 1994. Ex situ conservation of wild plant species: time to reassess the genetic assumptions and implications of seed banks. Conserv Biol 8: 3949. doi: 10.1046/j.1523-1739.1994.08010039.x

Hay, F. R., and R. J. Probert. 2013. Advances in seed conservation of wild plant species: a review of recent research. Conservation Physiology 1: $\cot 030$

Husband, B. C., and L. G. Campbell. 2004. Population responses to novel environments: implications for ex situ plant conservation. In: Ex situ plant conservation: supporting species survival in the wild. Island Press, Washington. E. O. Guerrant, K. Havens, and M. Maunder, Eds. Island Press, Washington. p. 231-266.

Johnson, G., F. C. Sorensen, J. B. St Clair, and R. C. Cronn. 2004. Pacific Northwest Forest Tree Seed Zones A template for native plants? Native Plants Journal 5: 131-140. doi: 10.2979/NPJ.2004.5.2.131
Malhi, Y., J. T. Roberts, R. A. Betts, T. J. Killeen, W. Li, and C. A. Nobre. 2008. Climate change, deforestation, and the fate of the Amazon. science 319: 169-172

Margules, C. R., and R. L. Pressey. 2000. Systematic conservation planning. Nature 405: 243-253. doi: $10.1038 / 35012251$

Maunder, M. 1992. Plant reintroduction: an overview. Biodiversity \& Conservation 1: 51-61. doi: 10.1007/BF00700250

Maunder, M., K. Havens, E. O. Guerrant Jr, D. A. Falk, and D. Falk. 2004. Ex situ methods: a vital but underused set of conservation resources. In: $E x$ situ plant consetvation. Supporting species survival in the wild. Island Press, Washington. E. O. Guerrant, K. Havens, and M. Maunder, Eds. Island Press, Washington. p. 3-20.

Menges, E. S. 1998. Evaluating extinction risks in plant populations. Springer, 49-65pp.

Osborne, P. E., and P. J. Seddon. 2012. Selecting suitable habitats for reintroductions: variation, change and the role of species distribution modelling. Reintroduction biology: integrating science and management 1

Pressey, R., and K. H. Taffs. 2001. Scheduling conservation action in production landscapes: priority areas in western New South Wales defined by irreplaceability and vulnerability to vegetation loss. Biol Conserv 100: 355-376. doi: 10.1016/S0006-3207(01)00039-8

Theilade, I., and L. Petri. 2003. Conservation of tropical trees ex situ through storage and use. Guidelines and Technical Notes No. 65. Danida Forest Seed Centre, Humlebaek, Denmark.

Walck, J., and K. Dixon. 2009. Time to future-proof plants in storage. Nature 462: 721-721. doi: $10.1038 / 462721 \mathrm{a}$

Walters, C., P. Berjak, N. Pammenter, K. Kennedy, and P. Raven. 2013. Preservation of recalcitrant seeds. Science 339: 915-916. doi: 10.1126/science.1230935 